Cite this: RSC Adv., 2014, 4, 20737

Received 28th February 2014

Accepted 28th April 2014

DOI: $10.1039 / c 4 r a 01788 a$

www.rsc.org/advances

\section{Mild and rapid surface initiated ring-opening polymerisation of trimethylene carbonate from cellulose $\uparrow$}

\begin{abstract}
Samuel A. Pendergraph, ${ }^{*}$ Gregor Klein, Mats K. G. Johansson and Anna Carlmark*
Surface initiated ring-opening polymerisation (SI-ROP) of trimethylene carbonate (1,3-dioxane-2-one, TMC) from cellulose surfaces has been studied for the first time. Specifically, organocatalytic systems employing 1,8-diazabicyclo[5.4.0]undec-7-ene (DBU) or 1,5,7-triazabicyclo[4.4.0]dec-5-ene (TBD) were implemented in the ROP of TMC, initiated by the hydroxyl groups on the cellulose chain, to form polymer grafts on the surface of filter papers. A sacrificial initiator was added to the reaction solution, resulting in the formation of free, unbound polymer formed in parallel to the surface grafting. The properties of the polymer grafted paper were studied utilising infrared spectroscopy, thermal gravimetric analysis, scanning electron microscopy and contact angle measurements. The free polymers were characterised with nuclear magnetic resonance spectroscopy and size exclusion chromatography. The grafting resulted in hydrophobic papers in as little as one minute and the ability to control the grafting length of the polymer from the surface was demonstrated by either altering the time of the polymerisation or the ratio of free initiator to monomer. This polymerisation route provides milder conditions than conventional metal-catalysed ROP, greatly reduces reaction times and thus is an attractive method for modification of natural biopolymers compared to previously described methods.
\end{abstract}

\section{Introduction}

The grafting of polymers from solid surfaces has been implemented as an effective technique to control the interfacial behaviour. ${ }^{1-7}$ Different approaches have been examined, which include conventional free radical polymerisations, ${ }^{8-10}$ as well as controlled techniques such as atom transfer radical polymerisation (ATRP), ${ }^{11-13}$ nitroxide mediated radical polymerisations (NMP), ${ }^{14,15}$ reversible addition fragmentation chain transfer $(\mathrm{RAFT}){ }^{16-21}$ and ring-opening polymerisation (ROP)., ${ }^{3,22-28}$ Controlled surface initiated polymerisation techniques have been applied to create well defined surfaces for a plethora of applications ranging from electronics, reinforced composites, optical devices and drug delivery vehicles. . $^{2,4,6,12,23,29,30}$

The modification of cellulosic materials has been a wellstudied challenge over the last several decades. ${ }^{23}$ The high modulus that is inherent for cellulose as well as the natural abundance and availability of the material continues to be the motivation for hybrid cellulosic based materials. ${ }^{23}$ However, realization of cellulose derived materials in several applications

KTH Royal Institute of Technology, School of Chemical Science and Engineering, Fibre and Polymer Technology, Teknikringen 56, SE-100 44, Stockholm, Sweden. E-mail: annac@kth.se; spender@kth.se

$\dagger$ Electronic supplementary information (ESI) available: An example ${ }^{1} \mathrm{H}-\mathrm{NMR}$ of the PTMC polymerisation and IR spectroscopy of the paper after 1 minute polymerisation are shown in the ESI. See DOI: 10.1039/c4ra01788a has been hindered due to the poor interfacial compatibility with many synthetic polymers. Conversely, surface polymerisations have been utilised to obviate poor adhesion between these interfaces. ${ }^{1,16,31,32}$ For example, inclusion of cellulosic materials into fibre reinforced composites has significantly increased in recent years. . $^{3,23,24,26,33}$

The aforementioned controlled polymerisation techniques have been studied in order to obtain versatile and functional surfaces. RAFT and ATRP polymerisations have successfully introduced characteristics on cellulose such as hydrophobicity, responsivity, and formation of precursor reactive groups. ${ }^{1,5,16,17,20,28,32,34,35}$ However, the utilisation of these synthetic routes requires a modification of the cellulose to introduce the necessary reactive/initiating group. Polyesterification reactions have been widely evaluated on different types of cellulose as they do not require an initial chemical modification of the interface..$^{3,22-28}$ In this reaction, the native hydroxyl groups in the polysaccharide backbone are utilised as initiators, which is a great advantage with this technique. However, despite several studies on polyester grafting, the reactions are typically focused on metal catalysed polymerisations, for the ROP of lactones and lactides. Hafrén and Cordova utilised an organic acid for the ROP of $\varepsilon$-caprolactone ( $\varepsilon$-CL) from a cellulosic substrate; however their procedures required high temperatures. ${ }^{36}$ Recently, our group has published a report of using a basic organocatalytic system which was employed (1,5,7-triazabicyclo[4.4.0]dec-5-ene (TBD)), for the grafting of 
$\varepsilon$-CL from a cellulose model surface. ${ }^{37}$ The use of these types of catalysts has been demonstrated to create well-controlled solution based polymers with short reaction times and under mild conditions. ${ }^{38}$

Lactones and lactides have proven to be versatile monomers in ROP from cellulose and demonstrate a potential for biomedical applications. ${ }^{39,40}$ The advantage of the resulting polyesters is their potential biodegradability as they are able to hydrolyse under in vivo conditions. However, one drawback with polyesters is the generation of acid by the formation of carboxylic acid groups during hydrolysis. Polycarbonates are a class of polymers which demonstrate similar potential for biomedical applications in terms of degradation under in vivo conditions; however they do not generate acidic by-products in the hydrolysis of the polymer..$^{\mathbf{2 9 , 4 1 - 4 5}}$ These characteristics have motivated us to study polycarbonates grafted from cellulose interfaces, which to our present knowledge have not been explored previously. In this report, we describe the first polymerisation of trimethylene carbonate (1,3-dioxane-2-one, TMC) from cellulosic fibre surfaces. Our method utilises organocatalytic bases to initiate ROP from paper fibres directly. We demonstrate the ability to create hydrophobic paper with tuneable control of the amount of polymer grafted on the surface. The reactions described herein are performed under milder conditions than previously reported work on ROP of lactones and lactides from cellulosic surfaces. Finally, we demonstrate the ability to create hydrophobic, polycarbonate functionalised papers within a minute at room temperature without prior modification of the cellulosic material.

\section{Experimental}

\section{Materials}

1,8-Diazabicyclo[5.4.0]undec-7-ene (DBU), 1,5,7-triazabicyclo [4.4.0]dec-5-ene (TBD), benzylic alcohol and benzoic acid were purchased from Sigma Aldrich and used as received. Dichloromethane (DCM) was purchased from VWR and used without further purification. Trimethylene carbonate (TMC) was synthesized according to literature procedures. ${ }^{46}$ Whatman \#1 filter paper was first washed with ethanol and DCM thoroughly. Subsequently, the paper was dried in an oven overnight (>12 hours) at $120{ }^{\circ} \mathrm{C}$ prior to the grafting polymerisation.

\section{Instrumentation}

Proton nuclear magnetic resonance $\left({ }^{1} \mathrm{H}-\mathrm{NMR}\right)$ spectra were recorded using a Bruker AM 400a with deuterated chloroform $\left(\mathrm{CDCl}_{3}\right)$ as the solvent. Molecular weight $\left(M_{\mathrm{n}}\right)$ and dispersity $\left(\emptyset_{\mathrm{M}}\right)$ were evaluated with size exclusion chromatography (SEC) with a TOSOH EcoSEC HLC-8320GPC system equipped with an EcoSEC RI detector and three columns (PSS PFG $5 \mu \mathrm{m}$, Microguard $100 \AA$ and $300 \AA$ ) (molecular weight resolution range: 300-100 $\left.000 \mathrm{~g} \mathrm{~mol}^{-1}\right)$ from PSS GmbH, using DMF $(0.2 \mathrm{~mL}$ $\min ^{-1}$ ) containing $0.01 \mathrm{M} \mathrm{LiBr}$ as the mobile phase at $50{ }^{\circ} \mathrm{C}$. The measurements were calibrated against a low dispersity poly(methyl methacrylate) (PMMA) standard ranging from 700 to $2000000 \mathrm{~g} \mathrm{~mol}^{-1}$.
Static contact angles were measured at $50 \% \mathrm{RH}$ and $23{ }^{\circ} \mathrm{C}$ on a KSV instrument CAM 200 equipped with a Basler A602f camera, using a volume of $5 \mu \mathrm{L}$ of Milli-Q water.

Infrared spectroscopy (IR) was conducted on a Perkin-Elmer Spectrum 2000 FT-IR with a MKII Golden Gate, Single Reflection ATR system from Specac Ltd., London, U.K. All spectra were normalised against a specific ATR crystal absorption (1900$2300 \mathrm{~cm}^{-1}$ ) in the comparison of the cellulose grafting.

Field emission scanning electron microscopy (FE-SEM) images were recorded on a Hitachi S-4800 FE-SEM and the samples were coated according to previously reported procedures. ${ }^{22}$

Thermal gravimetric analyses (TGA) were performed on a TGA/DSC 1 Mettler Toledo AG, Analytical Switzerland. Samples were subjected to a heating rate of $10{ }^{\circ} \mathrm{C} \mathrm{min}{ }^{-1}$ from 40 to $700{ }^{\circ} \mathrm{C}$ under nitrogen atmosphere with a flow rate of $60 \mathrm{~mL} \mathrm{~min}^{-1}$.

\section{Polymerisation of TMC on cellulose fibres}

The conditions for the TMC polymerisation were based on previously reported procedures in the literature. ${ }^{38,47}$ All polymerisations in the test series followed a general procedure as described below, varying reaction conditions as presented in Table 1. A vial containing a magnetic stir-bar was flame-dried. The papers ( 2 pieces with dimensions of $1.5 \times 0.5 \mathrm{~cm}$ ) were directly added from the drying oven and the vial was then capped with a rubber septum. The vial was evacuated and backfilled with argon to form a dry, inert atmosphere within the vial. After the vial had cooled down to room temperature, TMC $\left(0.5 \mathrm{~g}, 4.9 \times 10^{-3} \mathrm{~mol}\right)$ was added to the flask. The flask was subsequently evacuated and backfilled with argon for 10 minutes to remove oxygen and water. A fresh stock solution of benzylic alcohol $\left(8.5 \mathrm{mg} \mathrm{mL}^{-1}\right)$ in DCM was added, under argon, to introduce the sacrificial initiator. For example, in $250: 1$ reactions, $250 \mu \mathrm{L}$ of the benzylic stock solution $(2.12 \mathrm{mg}$, $\left.1.96 \times 10^{-5} \mathrm{~mol}\right)$ was added to the mixture. Catalyst stock solution (30 $\mathrm{mg} \mathrm{mL}^{-1}$ ) was added to the reaction mixture and the mixture was allowed to stir for one minute at room temperature to ensure dissolution of the monomer. In all experiments, the monomer to catalyst molar ratio was kept constant at a 100:1 ratio and the sample vials subsequently diluted with dry DCM under argon so the total volume of the reaction mixtures was $850 \mu \mathrm{L}$. The reaction mixture was then placed into an oil bath thermostated at $40{ }^{\circ} \mathrm{C}$ for a specified time. When the reaction was completed, the solution was quenched with benzoic acid in a 3 molar excess relative to the DBU catalyst. The modified paper was removed from the reaction solution and rinsed with DCM and ultrasonicated in DCM for 5 minutes to remove any physically adsorbed polymer. The solvent from the rinsing was transferred to the remaining reaction mixture and then concentrated in a rotary evaporator. The solution was then poured in an excess of methanol at $0{ }^{\circ} \mathrm{C}$ and the precipitated polymer collected for IR, ${ }^{1} \mathrm{H}-\mathrm{NMR}$ and SEC analysis. The paper was vacuum dried overnight at $50{ }^{\circ} \mathrm{C}$ prior to FTIR, TGA, SEM and contact angle measurements. Experiments using the TBD catalyst were conducted in the same manner as 
Table 1 Reaction conditions of the surface-initiated polymerisation of carbonate from filter paper

\begin{tabular}{|c|c|c|c|c|c|c|c|}
\hline Sample & Catalyst & Monomer/initiator ratio $[\mathrm{M}]$ & Time & Conversion (\%) & $M_{\mathrm{n}}^{b}(\mathrm{kDa})$ & $M_{\mathrm{n}}{ }^{c}(\mathrm{kDa})$ & $D_{\mathrm{M}}$ \\
\hline 1 & DBU & 250 & $3 \mathrm{~h}$ & 86 & 10 & 7.2 & 1.40 \\
\hline 2 & DBU & 250 & $6 \mathrm{~h}$ & 92 & 10 & 7.7 & 1.36 \\
\hline $4^{a}$ & DBU & - & $24 \mathrm{~h}$ & $>99$ & N/A & 61 & 1.43 \\
\hline 5 & TBD & 50 & $10 \mathrm{~min}$ & $>99$ & 5.0 & 4.7 & 1.86 \\
\hline 6 & TBD & 250 & $10 \mathrm{~min}$ & $>99$ & 10 & 6.9 & 1.33 \\
\hline
\end{tabular}

${ }^{a}$ No added sacrificial initiator. ${ }^{b}$ Calculated from end-group analysis by ${ }^{1} \mathrm{H}$-NMR. ${ }^{c}$ Measured by SEC.

DBU, except that the time was held constant at 10 minutes for all experiments. In a final experiment, the reaction was run for 1 minute and then quenched and processed identically to the other TBD and DBU reactions.

\section{Results and discussion}

The impetus of this study was to evaluate the characteristics of organocatalytic polymerisations of TMC from cellulose fibre surfaces. Filter paper (Whatman \#1) has previously proven to be a robust and reliable surface for polymerisations of a plethora of various monomers, owing to its high cellulosic content ( $>98 \%)$ and purity. ${ }^{31}$ While ROP and ring-opening metathesis polymerisation (ROMP) have been studied from cellulose fibres, limited work has been undertaken on understanding the behaviour of ring-opening reactions, catalysed by metal free organocatalysts. ${ }^{2,37}$ Furthermore, ROP of cyclic carbonates have not been previously reported from paper based materials. In order to evaluate the polymerisations from cellulose, we employed similar reactions conditions as reported by Waymouth, Hedrick and co-workers (Fig. 1) for polymerisation of TMC in solution, implementing the same catalysts on a heterogeneous system..$^{\mathbf{3}, \mathbf{4 7}}$
In most of the grafting reactions, a sacrificial initiator was added to the polymerisation solution, resulting in formation of free, unbound polymers. Previous work on grafting from cellulose utilising ATRP and RAFT have shown that polymer formed in the solution in parallel to the surface initiated ring-opening polymerisation (SI-ROP) has similar properties in terms of $M_{\mathrm{n}}$ and dispersity. ${ }^{16,48}$ It was anticipated that this would also be valid for SI-ROP of carbonates. Therefore, this methodology was also chosen for these experiments as surface-bound polycarbonates are challenging to cleave off the surface of cellulose fibres by conventional methods (e.g. hydrolysis) since this would also degrade the polymer itself. However, analysing the free polymer formed, and assuming that the free polymer and the surface bound polymer are similar, the molecular weight and dispersity $\left(\bigoplus_{\mathrm{M}}\right)$ of the brush can be indirectly determined. ${ }^{48}$

\section{Ring-opening polymerisation with DBU catalyst}

The free polymers formed were evaluated by SEC and ${ }^{1} \mathrm{H}-\mathrm{NMR}$ analysis, varying the reaction times to obtain the molar masses, conversions, and $\bigoplus_{\mathrm{M}}$ for both catalytic systems as presented in Table 1. DBU was utilised to evaluate the molecular weight dependence given a target molecular weight as a function of time. This catalyst was selected because it has previously been

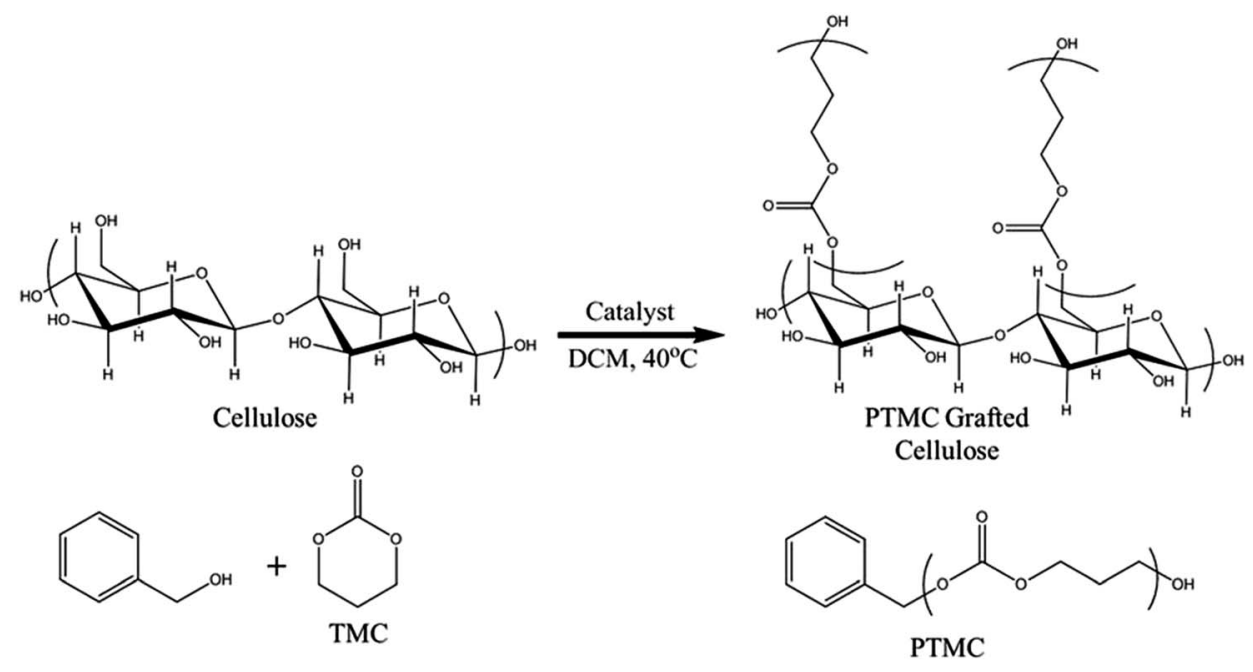

Fig. 1 Reaction scheme of the grafting polymerisation from the filter paper. 
established to exhibit slower reaction rates in the ROP of TMC compared to other more active organocatalysts (e.g. TBD). ${ }^{38,47} \mathrm{~A}$ relatively slow reaction rate allowed for a more distinct determination of the effect of reaction time (i.e. the reaction kinetics of a very rapid reacting system is difficult to practically assess utilising conventional analytical techniques). The conversion was measured by evaluating the up-field shift in the methylene peaks of the TMC monomer to the polymer, from $4.45 \mathrm{ppm}$ to $4.2 \mathrm{ppm}$ and from 2.2 to $2.0 \mathrm{ppm}$ (an example is provided in Fig. S1 $\dagger)^{38,47}$ Polymerisations catalysed with DBU at room temperature had virtually no conversion after 8 hours under inert conditions. However, when the temperature was raised to $40{ }^{\circ} \mathrm{C}$, the reaction proceeded in a linear manner up to 6 hours (sample 1 and 2) and subsequently neared completion after 6 hours according to the ${ }^{1} \mathrm{H}$-NMR data. Longer reaction times (sample 3, 24 hours) produced a paper with similar hydrophobic characteristics; however this also lead to a broadening of the $\emptyset_{M}$ of the free forming polymer, which was consistent with previously reported results. ${ }^{\mathbf{3 8 , 4 7}}$ The ability of cellulose to initiate TMC polymerisation without any sacrificial initiator in the reaction mixture $([\mathrm{TMC}] /[\mathrm{DBU}]=100)$ was also investigated. As no free initiator was added, free polymers were not expected to be formed. However, after precipitation of the reaction solution, a polymer which had higher molecular weight compared to the other reactions could be isolated. We propose that this polymer was formed from remaining water molecules, which could function as initiators, or from other side reactions that could potentially occur, such as chain scission of the propagating brushes, cleaving chains off the surface. It should in this context be noted that it is well known that it is very difficult to completely remove bound water from cellulose due to its hygroscopic structure. ${ }^{48}$ The procedure used in the present study was, however, in accordance to the state of the art in minimising the water content under conventional laboratory conditions. The high molar mass obtained further implies that a high concentration of monomers compared to free initiator functions was found in this system.

The grafted cellulose surfaces were analysed by contact angle measurements, IR spectroscopy, SEM and TGA. Static contact angle measurements were performed on the grafted cellulose and compared to native cellulose surfaces. It should here be noted that the two main factors affecting the macroscopic contact angle determined in this study was the surface energy (surfaces tension) measured on an Angström-level and the surface topography measured over a length scale ranging from nanometres to micrometers. ${ }^{49}$ Native cellulose paper had no measureable contact angle due to its highly hydrophilic nature. However, the polycarbonate grafted filter papers exhibited stable static contact angles of $100 \pm 3$ degrees for reaction times of 3 hours or more for the DBU catalysed reactions as shown in Fig. 2. Prolonged reaction times did not increase the contact angles above these values which imply that this was the intrinsic surface behaviour of PTMC surfaces for this specific surface topology. The contact angles were relatively independent of molecular weight and reaction times indicating that the surface on the Ångström-level was rather homogeneous and above a threshold level above which a chain extension do not

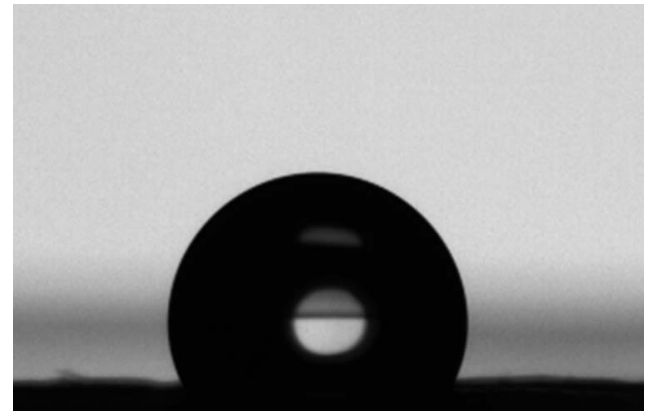

Fig. 2 Contact angle of a PTMC grafted paper after polymerisation (24 hours) with the DBU catalyst at $250: 1$ monomer/initiator ratio.

contribute to further changes in surface energy. The contact angles of $100^{\circ}$ were considerably larger than previously reported literature values for PTMC films $\left(\sim 75^{\circ}\right) .{ }^{41}$ The discrepancy between our values and thin films of PTMC prepared in literature was due to the roughness in the filter paper. In Fig. 3, SEM images are shown for the unmodified paper and for 24 hours of polymerisation with DBU. The unmodified fibres had a rough exterior due to the fibrillar structure of the cellulose fibres. The polycarbonate grafted filter paper appeared to have a smoother surface and the total paper was less porous overall, which is consistent to our previous observations. ${ }^{22}$

IR spectroscopy was performed on the grafted filter papers to confirm the attachment of polymers to the surface. Unmodified cellulose does not possess carbonyl functional groups, and therefore they do not have IR adsorption between 1600$1800 \mathrm{~cm}^{-1}$. The reference sample of unmodified filter paper shows no significant peak in this region, as shown in Fig. 4. The pure polycarbonate (PTMC), isolated from the reaction, shows a large stretch vibration around $1750 \mathrm{~cm}^{-1}$, which is characteristic of a carbonate carbonyl $\mathrm{C}=\mathrm{O}$ stretching vibration The papers grafted with TMC for 3 hours, exhibited a peak appearing at $1750 \mathrm{~cm}^{-1}$, originating from the carbonate grafted onto the surface. Increasing the polymerisation time to 6 hours, increased the peak in the $1750 \mathrm{~cm}^{-1}$ region, with an even stronger absorption observed for the samples grafted for 24 hours. The increased absorption was indicative of a higher PTMC polymer content on the surface. The increased PTMC content could have arisen from two possibilities. First, the increased time of the reaction allowed for the monomers to propagate, thus creating longer chains assuming a constant grafting density of the chains. Second, continuing reactions of unmodified hydroxyl groups either through grafting-from the surface or PTMC homopolymers grafting-to the surface could have increased the grafting density. ${ }^{38,47}$ Conversely, we attributed the increase in the carbonyl signal in IR primarily to increasing the molecular weight of the grafted polymer chains due to steric hindrance. Interestingly, this increased amount of polymer on the paper differed from the trend of the data obtained from the SEC and NMR analysis of the free formed polymers, Table 1 , entries $1-3$. As can be seen, the molecular weights of the free forming polymers are similar in all cases, regardless of the variation in reaction time. 

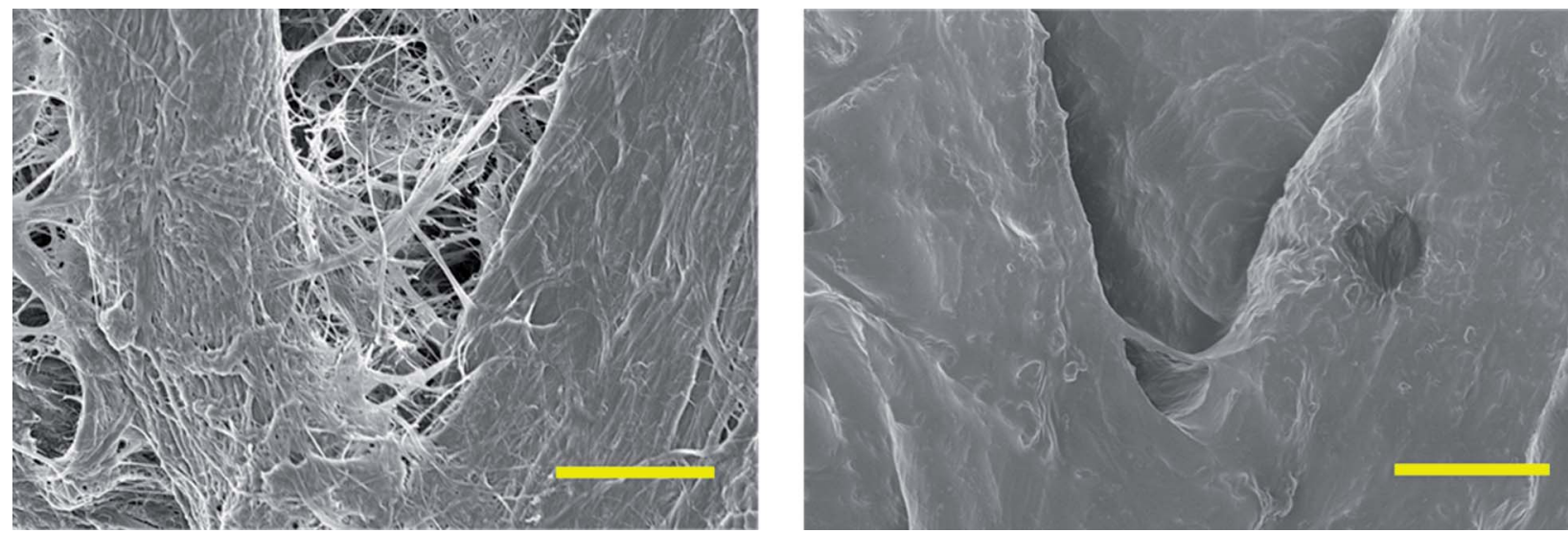

Fig. 3 SEM images of unmodified filter paper (left) and PTMC grafted paper (sample 4). The scale bar in both samples is $10 \mu \mathrm{m}$.

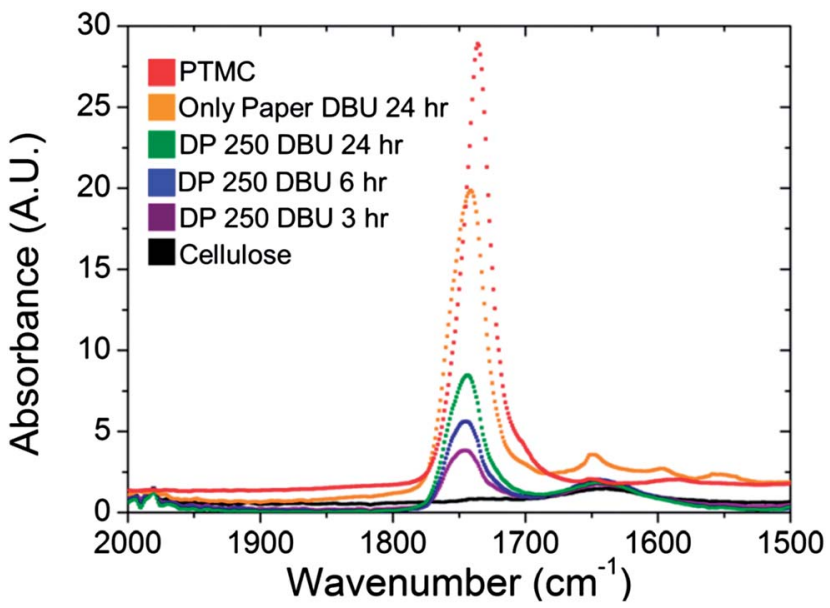

Fig. 4 IR spectroscopy on PTMC grafted paper (samples 1-4, Table 1), unmodified cellulose and bulk PTMC (extracted from sample 4). The range displayed illustrates the presence of a carbonyl peak due to the carbonate functionality at $1750 \mathrm{~cm}^{-1}$.

There appeared to be an upper limit to the molecular weight of this polymerisation, which can occur with higher targeted molecular weights of TMC. ${ }^{38,47}$ It could be that the surfaceinitiated polymerisation and the free polymerisation do not follow the same reaction conditions, as in the case of SI-ATRP of cellulose, and that side-reactions are occurring at a higher rate in the bulk polymerisation compared to the surface-bound polymerisation. ${ }^{32}$ In sample 4 , no sacrificial initiator was added to the grafting reaction which resulted in a stronger adsorption peak in IR, suggesting that a considerably higher molecular weight polymer had been grafted to the surface in this case. Regardless of the absence of free initiator, a free polymer was formed in bulk, likely initiated from remaining water molecules in the system. As can be seen in Table 1, entry 4, this polymer has considerably higher molecular weight than the ones formed from the free initiator. Furthermore, as this polymer did not contain any benzylic methylene end-groups, no calculations regarding the molecular weight could be performed from ${ }^{1} \mathrm{H}$ NMR.

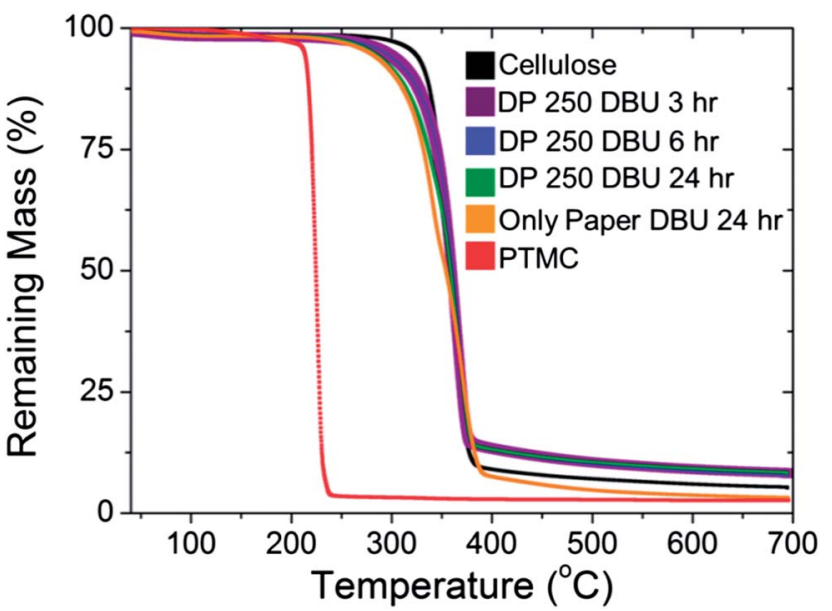

Fig. 5 TGA of unmodified cellulose, bulk PTMC (from sample 4) and PTMC grafted paper (samples 1-4, Table 1).

The samples polymerised with DBU were analysed with TGA to evaluate the thermal properties of the polycarbonate grafted filter paper in comparison to unmodified papers and PMTC homopolymer. As shown in Fig. 5, there was a significant difference in degradation temperature between the PTMC and the unmodified cellulose paper. PTMC had an onset of thermal degradation temperature of around $240{ }^{\circ} \mathrm{C}$, followed by a precipitous decline in mass. The low temperature for degradation of PTMC has been attributed to the depolymerisation of the carbonate group in the backbone. ${ }^{\mathbf{4}}$ Conversely, unmodified cellulose had the highest degradation temperature, over $100{ }^{\circ} \mathrm{C}$ more than PTMC. As expected, when the degree of polymerisation of the grafted polymer increased, the temperature where the onset of thermal degradation occurred was lowered. This was expected; when the mass content of the PTMC was increased, the mass content should begin to show the onset of degradation at a lower temperature. Previous degradation studies with copolymers of PTMC and other polyesters have shown that increasing TMC content shifts the onset of degradation closer towards the pure PTMC degradation 
temperature. ${ }^{42}$ Furthermore, despite a significant difference in the degradation temperature of the polyesters and PTMC, they observed a singular decrease in the mass and not a multi-step system. ${ }^{42}$

\section{Rapid polymerisation of cellulose utilising TBD}

The polymerisation of TMC from cellulose was controllable with the use of DBU as a catalyst over several hours, however the polymerisation times required were around 8 hours for total conversion of the monomer. In order to reduce the reaction times, a more active catalyst, TBD, was also investigated for the SI-ROP of TMC. ${ }^{38,47}$ In the experiments, the polymerisation with TBD had conversions of over $99 \%$ in less than 10 minutes. Therefore, another strategy to control the molecular weight grafted to the paper was implemented. Using TBD as the catalyst, the target molecular weight was adjusted rather than the reaction time. Three different molecular weights were targeted by altering the amount of sacrificial initiator.

As shown with entries 5 and 6 in Table 1, the resulting free forming polymer characteristics are shown. The increase in dispersity for the DP of 50 versus 250 was attributed to the rapid conversion and subsequent chain transfer reactions which broaden the $\bigoplus_{\mathrm{M}}$, similar to sample 3 in the DBU polymerisation. ${ }^{38,47}$ The polycarbonate grafted papers utilising TBD as catalyst were analysed in the same manner as the ones catalysed by DBU. In Fig. 6, the IR spectra of all the grafted filter papers are shown and compared to neat filter paper and PTMC. The carbonate peak at $1750 \mathrm{~cm}^{-1}$ was increasing with higher target molecular weight after 10 minutes of polymerisation. The reduction in the sacrificial initiator produced higher molecular masses on the paper. The filter paper possessed comparable hydrophobic contact angle characteristics to the DBU catalysed reactions.

However, we wanted to explore how quickly the polymerisation could be implemented for the paper to become hydrophobic. Another reaction was run for 1 minute (target DP $=100$ ) with TBD and subsequently quenched. The reaction was run to

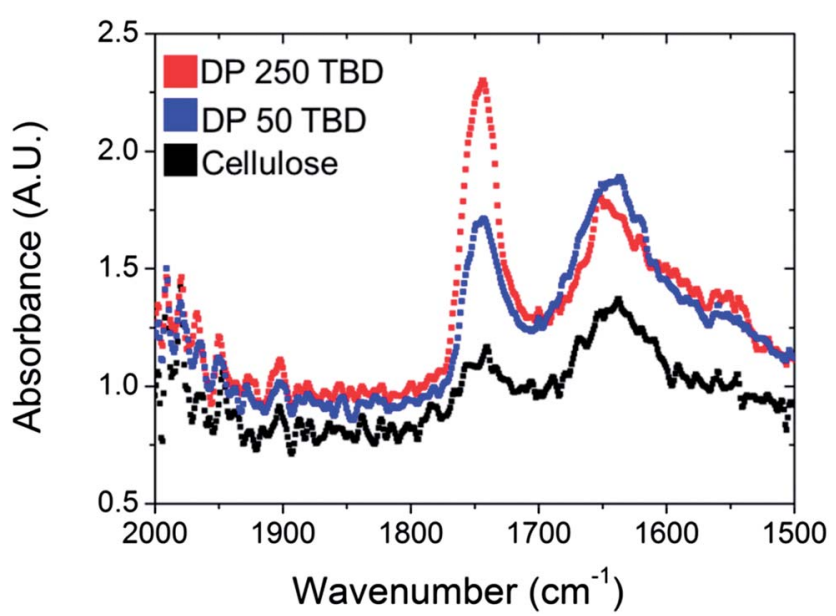

Fig. 6 IR spectroscopy of PTMC grafted papers (samples 5 and 6 , Table 1) and unmodified paper.

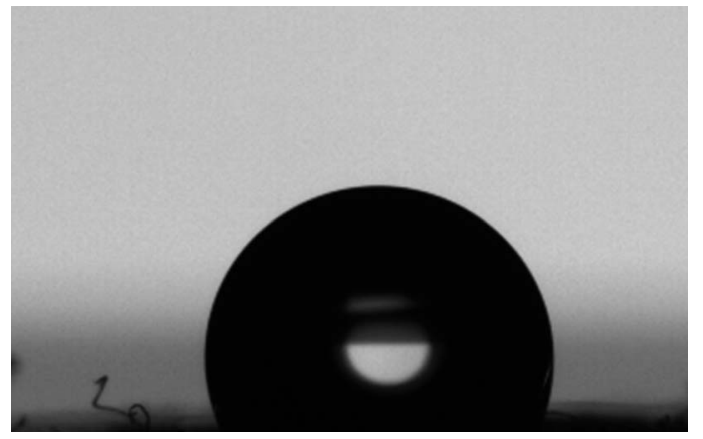

Fig. 7 Contact angle of PTMC grafted paper after 1 minute of reaction time and subsequent quenching of the polymerisation.

over $99 \%$ conversion confirmed by NMR. The grafting of the paper was confirmed by IR spectroscopy (Fig. S2 $\dagger$ ), where there is a sharp increase in absorption at $1750 \mathrm{~cm}^{-1}$. After processing the paper, the sample was tested for contact angle; the paper was equally as hydrophobic $(104 \pm 3)$ as the previous DBU samples after 24 hours (Fig. 7). The ability for unmodified paper to become transformed in very little time can potentially enable the use of functional polycarbonates to create new applications from cellulosic materials. We anticipate these findings to be a valuable procedure to not only introduce new functional groups, but to also quickly introduce interesting polymer architectures off of cellulosic interfaces.

\section{Conclusions}

Herein, the first SI-ROP of carbonates from cellulose surfaces was reported. Organocatalysts were implemented to demonstrate controlled polymerisation with tuneable grafting lengths on the paper. The polymerisations can be implemented without prior functionalization of the cellulose. Ring-opening polymerisations of TMC resulted in hydrophobic papers and the grafted polymer on the surface could be tailored through two different routes. The grafting content could be tuned by adjusting the reaction time when DBU catalyst was employed or by varying the ratio of monomer to initiator when utilising the more active TBD catalyst. Rapid grafting polymerisations (1 min) were achieved with the use of TBD on filter paper. Implementing organocatalysts with TMC allows a biomedical relevant polymer to be grafted to the surface of a cellulose substrate without metal impurities in the system. The use of cyclic carbonate monomers with TBD can be used as a potential strategy to easily and rapidly introduce functionality onto unmodified cellulosic substrates under mild conditions. The combination of the speed of the reaction and the preclusion modification steps in paper prior to polymerisation can enable this as a potential synthetic route for industrial applications.

\section{Acknowledgements}

The authors greatly acknowledge the KAMI foundation for financial support. 


\section{Notes and references}

1 A. Aied, Y. Zheng, A. Pandit and W. X. Wang, ACS Appl. Mater. Interfaces, 2012, 4, 826-831.

2 C. J. Fristrup, K. Jankova and S. Hvilsted, Soft Matter, 2009, 5, 4623-4634.

3 H. Lönnberg, K. Larsson, T. Lindström, A. Hult and E. Malmström, ACS Appl. Mater. Interfaces, 2011, 3, 1426-1433.

4 S. H. Park, H. S. Lee, J. D. Kim, D. W. Breiby, E. Kim, Y. D. Park, D. Y. Ryu, D. R. Lee and J. H. Cho, J. Mater. Chem., 2011, 21, 15580-15586.

5 J. O. Zoppe, Y. Habibi, O. J. Rojas, R. A. Venditti, L. S. Johansson, K. Efimenko, M. Österberg and J. Laine, Biomacromolecules, 2010, 11, 2683-2691.

6 M. A. C. Stuart, W. T. S. Huck, J. Genzer, M. Muller, C. Ober, M. Stamm, G. B. Sukhorukov, I. Szleifer, V. V. Tsukruk, M. Urban, F. Winnik, S. Zauscher, I. Luzinov and S. Minko, Nat. Mater., 2010, 9, 101-113.

7 B. Zhao and W. J. Brittain, Prog. Polym. Sci., 2000, 25, 677710.

8 R. C. Advincula, J. Dispersion Sci. Technol., 2003, 24, 343-361. 9 B. de Boer, H. K. Simon, M. P. L. Werts, E. W. van der Vegte and G. Hadziioannou, Macromolecules, 2000, 33, 349-356.

10 F. Khelifa, S. Ershov, Y. Habibi, R. Snyders and P. Dubois, ACS Appl. Mater. Interfaces, 2013, 5, 11569-11577.

11 D. Plackett, K. Jankova, H. Egsgaard and H. S. Hvilsted, Biomacromolecules, 2005, 6, 2474-2484.

12 K. Matyjaszewski and N. V. Tsarevsky, Nat. Chem., 2009, 1, 276-288.

13 J. Pyun, T. Kowalewski and K. Matyjaszewski, Macromol. Rapid Commun., 2003, 24, 1043-1059.

14 C. Bartholome, E. Beyou, E. Bourgeat-Lami, P. Chaumont, F. Lefebvre and N. Zydowicz, Macromolecules, 2005, 38, 1099-1106.

15 C. Bartholome, E. Beyou, E. Bourgeat-Lami, P. Chaumont and N. Zydowicz, Macromolecules, 2003, 36, 7946-7952.

16 M. Barsbay, G. Guven, M. H. Stenzel, T. P. Davis, C. BarnerKowollik and L. Barner, Macromolecules, 2007, 40, 7140-7147.

17 C. Li, J. Han, C. Y. Ryu and B. C. Benicewicz, Macromolecules, 2006, 39, 3175-3183.

18 G. Moad, E. Rizzardo and S. H. Thang, Aust. J. Chem., 2005, 58, 379-410.

19 D. Roy, J. T. Guthrie and S. Perrier, Macromolecules, 2005, 38, 10363-10372.

20 D. Roy, J. S. Knapp, J. T. Guthrie and S. Perrier, Biomacromolecules, 2008, 9, 91-99.

21 M. Semsarilar, V. Ladmiral and S. J. Perrier, J. Polym. Sci., Part A: Polym. Chem, 2010, 48, 4361-4365.

22 L. Carlsson, E. Malmström and A. Carlmark, Polym. Chem., 2012, 3, 727-733.

23 S. J. Eichhorn, A. Dufresne, M. Aranguren, N. E. Marcovich, J. R. Capadona, S. J. Rowan, C. Weder, W. Thielemans, M. Roman, S. Renneckar, W. Gindl, S. Veigel, J. Keckes, H. Yano, K. Abe, M. Nogi, A. N. Nakagaito, A. Mangalam, J. Simonsen, A. S. Benight, A. Bismarck, L. A. Berglund and T. Peijs, J. Mater. Sci., 2010, 45, 1-33.
24 Y. Habibi, A. L. Goffin, N. Schiltz, N. E. Duquesne, P. Dubois and A. Dufresne, J. Mater. Chem., 2008, 18, 5002-5010.

25 M. Labet and W. Thielemans, Cellulose, 2011, 18, 607-617.

26 M. Labet and W. Thielemans, Polym. Chem., 2012, 3, 679684.

27 H. Lönnberg, Q. Zhou, H. Brumer, T. T. Teeri, E. Malmström and A. Hult, Biomacromolecules, 2006, 7, 2178-2185.

28 E. Östmark, D. Nyström and E. Malmström, Macromolecules, 2008, 41, 4405-4415.

29 A. C. Engler, J. M. W. Chan, K. Fukushima, D. J. Coady, Y. Y. Yang and J. L. Hedrick, ACS Macro Lett., 2013, 2, 332336.

30 S. C. M. Fernandes, P. Sadocco, A. Aonso-Varona, T. Palomares, A. Eceiza, A. J. D. Silvestre, I. Mondragon and C. S. R. Freire, ACS Appl. Mater. Interfaces, 2013, 5, 3290-3297.

31 A. Carlmark and E. Malmström, J. Am. Chem. Soc., 2002, 124, 900-901.

32 S. Hansson, T. Tischer, A. S. Goldmann, A. Carlmark, C. Barner-Kowollik and E. Malmström, Polym. Chem., 2012, 3, 307-309.

33 E. Espino-Perez, J. Bras, V. Ducruet, A. Guinault, A. Dufresne and S. Domenek, Eur. Polym. J., 2013, 49, 3144-3154.

34 A. Carlmark and E. E. Malmström, Biomacromolecules, 2003, 4, 1740-1745.

35 T. Tischer, A. S. Goldmann, A. K. Linkert, V. Trouillet, H. G. Borner and C. Barner-Kowollik, Adv. Funct. Mater., 2012, 22, 3853-3864.

36 J. Hafrén and A. Cordova, Macromol. Rapid Commun., 2005, 26, 82-86.

37 L. Carlsson, S. Utsel, L. Wågberg, E. Malmström and A. Carlmark, Soft Matter, 2012, 8, 512-517.

38 M. K. Kiesewetter, E. J. Shin, J. L. Hedrick and R. M. Waymouth, Macromolecules, 2010, 43, 2093-2107.

39 A.-C. Albertsson and I. K. Varma, Biomacromolecules, 2003, 4, 1466-1486.

40 A. Lendlein and R. Langer, Science, 2002, 296, 1673-1676.

41 O. S. Kluin, H. C. van der Mei, H. J. Busscher and D. A. Neut, Biomaterials, 2009, 30, 4738-4742.

42 Y. Marquez, L. Franco and J. Puiggali, Thermochim. Acta, 2012, 550, 65-75.

43 J. Mindemark, J. Hilborn and T. Bowden, Macromolecules, 2007, 40, 3515-3517.

44 H. Wang, J. H. Dong, J. K. Y. Qiu and Z. W. Gu, J. Polym. Sci., Part A: Polym. Chem, 1998, 36, 1301-1307.

45 K. J. Zhu, R. W. Hendren, K. Jensen and C. G. Pitt, Macromolecules, 1991, 24, 1736-1740.

46 T. Ariga, T. Takata and T. Endo, J. Polym. Sci., Part A: Polym. Chem, 1993, 31, 581-584.

47 F. Nederberg, B. G. G. Lohmeijer, F. Leibfarth, R. C. Pratt, J. Choi, A. P. Dove, R. M. Waymouth and J. L. Hedrick, Biomacromolecules, 2007, 8, 153-160.

48 S. Hansson, V. Trouillet, T. Tischer, A. S. Goldmann, A. Carlmark, C. Barner-Kowollik and E. Malmström, Biomacromolecules, 2013, 14, 64-74.

49 L. C. Gao and T. J. McCarthy, Langmuir, 2009, 25, 1410514115. 